\title{
Explorando problemas arqueológicos com técnicas físico-químicas: a trajetória do Grupo de Estudos Arqueométricos do Instituto de Pesquisas Energéticas e Nucleares, São Paulo, Brasil Exploring archaeological problems with physico-chemical techniques: the trajectory of the Group of Archaeometric Studies of the Nuclear and Energy Research Institute, São Paulo, Brazil
}

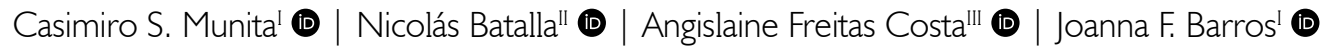

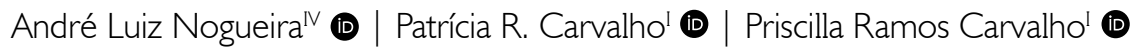 \\ Universidade de São Paulo. Instituto de Pesquisas Energéticas e Nucleares. São Paulo, São Paulo, Brasil \\ "Universidade de São Paulo. Museu de Arqueologia e Etnologia. São Paulo, São Paulo, Brasil \\ I'Universidade Federal do Rio de Janeiro. Museu Nacional. Rio de Janeiro, Rio de Janeiro, Brasil \\ IVInstituto Federal de Sergipe. Aracaju, Sergipe, Brasil
}

\begin{abstract}
Resumo: O presente artigo traz uma revisão da principal literatura produzida pelo Grupo de Estudos Arqueométricos do Instituto de Pesquisas Energéticas e Nucleares, Comissão Nacional de Energia Nuclear, de São Paulo (IPEN-CNEN/SP), criado em 1997, como consequência de uma iniciativa internacional para motivar o uso de técnicas nucleares para caracterização de materiais arqueológicos. Desde aquele momento, e até hoje, o grupo tem desenvolvido parcerias com pesquisadores/as de diferentes regiões do Brasil e de outros países para oferecer subsídios à compreensão interdisciplinar das cadeias operatórias de produção da cerâmica. Além disso, também vem aportando dados para o estudo multielementar e mineralógico de depósitos arqueológicos. Ao descrever brevemente os princííios das técnicas empregadas e a síntese dos resultados obtidos para cada estudo de caso, o objetivo foi demonstrar a contribuição das análises físico-químicas para questões relacionadas a aspectos culturais, como escolhas tecnológicas compartilhadas, redes de trocas e interações sociais em diferentes períodos do passado.
\end{abstract}

Palavras-chave: Arqueometria. Técnicas físico-químicas. Cerâmica arqueológica. Cadeias operatórias. Depósitos arqueológicos. História da ciência no Brasil.

Abstract: The present paper brings together key literature produced by the Group of Archaeometric Studies of the Nuclear and Energy Research Institute, IPEN - National Nuclear Energy Commission (São Paulo, Brazil). This group was founded in 1997, as a result of an international initiative to encourage the use of nuclear techniques for the characterization of archaeological materials. Since then, the Group has developed interdisciplinary partnerships with researchers from Brazil and other countries to offer analytical tools for unraveling ceramic chaine opératoires in different contexts. Such studies have contributed towards wider cultural interpretations regarding shared technological choices and artifact exchange networks in different social groups. Recently, the Group has also used multi-elemental and mineralogical techniques to tackle questions over the formation of archaeological deposits. This paper briefly explains the analytical principles of the employed techniques, and emphasizes how the results of each case study contribute to the interpretation of specific archaeological problems.

Keywords: Archaeometry. Physico-chemical techniques. Archaeological pottery. Chaîne opératoires. Archaeological deposits. History of science in Brazil.

Munita, C. S., Batalla, N., Costa, A. F., Barros, J. F., Nogueira, A. L., Carvalho, P. R., \& Carvalho, P. R. (2020). Explorando problemas arqueológicos com técnicas físico-químicas: a trajetória do Grupo de Estudos Arqueométricos do Instituto de Pesquisas Energéticas e Nucleares, São Paulo, Brasil. Boletim do Museu Paraense Emílio Goeldi. Ciências Humanas, 15(3), e20200004. doi: 10.1590/2178-2547-BGOELDI-2020-0004

Autor para correspondência: Casimiro S. Munita. Universidade de São Paulo. Instituto de Pesquisas Energéticas e Nucleares/CERPq. Av. Prof Lineu Prestes, 2242 - Cidade Universitária. São Paulo, SP, Brasil. CEP 05501-000 (camunita@ipen.br).

Recebido em 03/02/2020

Aprovado em 23/03/2020

Responsabilidade editorial: Cristiana Barreto 


\section{INTRODUÇÃO}

No Brasil, a arqueometria, no seu sentido mais abrangente (i.e. uso da ciência dos materiais na arqueologia e na ciência da conservação, segundo Artioli, 2010), é um vasto campo estabelecido há várias décadas. Além das análises de artefatos provenientes de coleções e de sítios arqueológicos, de sedimentos e solos que constituem os referidos sítios, a arqueometria brasileira tem contribuído com relevantes aportes no estudo de obras de arte e no campo da conservação de objetos, que fazem parte do patrimônio cultural'.

O Grupo de Estudos Arqueométricos do Instituto de Pesquisas Energéticas e Nucleares (IPEN), por meio da Comissão Nacional de Energia Nuclear (daqui em diante, IPEN-CNEN/SP), autarquia associada à Universidade de São Paulo, teve suas origens na confluência de vários países do mundo com disponibilidade de reatores nucleares de pesquisa, incluídos Argentina, Brasil, Chile, Peru, Cuba, USA e México, em um projeto internacional sobre técnicas analíticas nucleares aplicadas às pesquisas arqueológicas, sob os auspícios da Agência Internacional de Energia Atômica (IAEA, pela sua sigla em inglês). Tal projeto, denominado simplesmente como "Co-ordinated Research Project" (CRP F.2.30.15), teve seu primeiro encontro no Instituto Smithsonian, da cidade de Washington, DC (Estados Unidos), em junho de 1997, tendo como objetivo geral o de integrar cientistas analíticos e arqueólogos/as na abordagem de problemas de cunho arqueológico, desde a sua definição até a interpretação dos dados (International Atomic Energy Agency, 2003). A participação do Brasil no evento contou com a presença do Prof. Casimiro S. Munita, do IPEN-CNEN/SP, especialista em química nuclear, e da arqueóloga Profa. Márcia Angelina Alves, do Museu de Arqueologia e Etnologia da Universidade de São Paulo (MAE-USP), que tiveram interesse em desenvolver a interface da química nuclear com a arqueologia.
Dessa forma, o presente artigo tem por objetivo realizar uma revisão da trajetória do Grupo de Estudos Arqueométricos do IPEN-CNEN/SP, com destaque para os principais problemas arqueológicos abordados nas colaborações desenvolvidas com diferentes instituições. Nas primeiras três seções, são apresentados o desenvolvimento e os princípios das técnicas analíticas e estatísticas empregadas pelo grupo. Na sequência, é demonstrada a contribuição que o grupo tem dado nas interpretações arqueológicas, aplicando essas técnicas nos artefatos cerâmicos das diferentes regiões do Brasil (Sudeste, Nordeste e Norte) e do exterior (Oriente Próximo). Por fim, a última seção debruça-se sobre as contribuições mais recentes no aporte de dados multielementares e mineralógicos para a compreensão de processos de formação de sítios arqueológicos.

\section{PRIMEIRAS PESQUISAS E TÉCNICAS UTILIZADAS PELO GRUPO}

Um estudo de fragmentos cerâmicos recuperados em dois sítios arqueológicos do Sudeste brasileiro, realizado a partir de 1997, foi o âmbito inicial para o desenvolvimento dos princípios por trás das abordagens metodológicas e técnicas das pesquisas arqueométricas da equipe do IPEN. Em colaboração com a arqueóloga Profa Márcia Angelina Alves, do MAE-USP, o estudo (Munita et al., 1997; Munita et al., 2000a, 2000b; Goulart et al., 2005) envolveu a comparação do sítio Água Limpa (município de Monte Alto, estado de São Paulo) com o sítio Prado (município de Perdizes, estado de Minas Gerais), acrescentando-se, posteriormente, o sítio Rezende (município de Centralina, estado de Minas Gerais) (Munita et al., 2001a), aos efeitos de determinar as potencialidades da técnica multielementar de análise por ativação com nêutrons instrumental (daqui em diante, INAA, pela sua sigla em inglês) na detecção das diferenças na composição da matéria-prima utilizada

Algumas sínteses constam em Fleming (2008), J. Costa et al. (2009), M. Costa et al. (2009), Rizzutto et al. (2009), Bellido e Latini (2013), Kern et al. (2013) e Appoloni (2018). 
na confecção da cerâmica por parte das populações indígenas (ver resultados no tópico "As cerâmicas do Sudeste brasileiro").

Em primeiro lugar, a preocupação esteve concentrada na avaliação da precisão, exatidão e sensibilidade da técnica para a detecção de múltiplos elementos em materiais de composição conhecida, certificados por instituições internacionais, o que foi desenvolvido em nível nacional e internacional em comparações interlaboratoriais (Munita et al., 2001b). Enquanto a precisão se refere à reprodutibilidade de uma análise, a exatidão e a sensibilidade fazem referência à proximidade de uma medição elementar à sua concentração na amostra e à quantidade mínima de um elemento que pode ser detectado pela técnica, respectivamente (Bishop et al., 1990). As avaliações iniciais mediante análise de materiais certificados foram contempladas entre os principais objetivos da interface arqueológica desenvolvida pela International Atomic Energy Agency (2003), e constituem também um requisito fundamental para o uso da química analítica quantitativa, de maneira confiável (Pollard et al., 2007). Nos materiais como os Standard Reference Material (SRM), produzidos pelo National Institute of Standards and Technology (NIST), dos Estados Unidos, foram estabelecidos os valores certificados para os materiais de referência aceitos para a determinação de composição mediante INAA².

Em segundo lugar, a equipe concentrou seus esforços na avaliação dos métodos estatísticos apropriados para estudo dos resultados obtidos por INAA. Uma estreita colaboração com matemáticos/as foi estabelecida desde o começo (e.g. Munita et al., 2000a, 2000b; Oliveira \& Munita, 2003) e continua até hoje (ver a seção "A matemática envolvida: breve descrição", neste artigo), para determinação das análises necessárias para distinguir, sob um nível de confiança estatística especificada, os grupos composicionais das pastas nas cerâmicas arqueológicas.

\section{A FÍSICO-QUÍMICA ENVOLVIDA: OS PRINCÍPIOS ANALÍTICOS}

O grupo tem utilizado desde o começo a técnica multielementar de INAA, que está baseada no bombardeamento com nêutrons dos elementos presentes numa amostra para produzir isótopos radioativos artificiais, que são identificados e medidos (Glascock, 1992; Munita et al., 2019). A fonte de nêutrons usada pelo grupo é o reator nuclear de pesquisas do IPEN (no Centro do Reator de Pesquisas - CRPq), no qual os nêutrons são produzidos como resultado da fissão termal induzida por nêutrons de urânio $\left({ }^{235} \cup\right)$. Os radioisótopos resultantes do impacto dos nêutrons com os núcleos-alvo emitem partículas ou raios-gama atrasados (delayed gamma rays), característicos de cada elemento, num processo espontâneo e estatístico de transformação de átomos, conhecido como decaimento radioativo, e governado pela meia-vida do radioisótopo (Munita et al., 2019). A meia-vida é o período necessário para o decaimento da metade do número de átomos radioativos iniciais na amostra (ver Munita, 2005).

Os procedimentos de preparação das amostras de cerâmica e sedimento são relativamente simples e semelhantes, consistindo na obtenção de um pó homogêneo; no caso da cerâmica, é obtido mediante à realização de pequenos orifícios com furadeira e velocidade variável na lateral do fragmento; enquanto, no sedimento, é macerado em almofariz de ágata e peneirado em peneira de polietileno com abertura de 100 mesh. Após a secagem em estufa, segue um processo de pesagem e selagem de 100-150 mg do pó em invólucros de polietileno, embrulhados em papel de alumínio. Grupos de amostras empilhadas são colocados no interior de um invólucro cilíndrico de alumínio e enviados para irradiação. Os detalhes desses procedimentos foram descritos ao longo

\footnotetext{
2 Ver seção seguinte.
} 
da obra do grupo e podem ser lidos de forma resumida em Munita (2005, p. 171).

Na determinação da atividade e do número de átomos radioativos em uma amostra, consideram-se diversas variáveis, cuja menção excede os objetivos da presente revisão ${ }^{3}$. Aqui é suficiente dizer que o grupo tem trabalhado até hoje usando o método comparativo do INAA, o qual se fundamenta na irradiação de uma alíquota de uma amostra-padrão, de concentração conhecida, de forma conjunta com as amostras (cerâmica ou sedimento) cuja concentração se quer determinar. A amostra-padrão é um material muito puro e multielementar, como o já mencionado SRM produzido pela NIST.

Além do SRM, o grupo tem irradiado junto com as amostras alíquotas de materiais certificados por laboratórios internacionais de ampla distribuição (denominados reference material ou RM) para controle de qualidade analítico ${ }^{4}$. Para a detecção do espectro de raios-gama característicos, o grupo utiliza, hoje, um espectrômetro com detector de germânio hiperpuro (HPGe), modelo GX1925, da empresa Canberra.

grupo tem utilizado outras técnicas, segundo os objetivos dos estudos, em parceria com diversas instituiç̧̃̃es nacionais. A determinação da composição mineralógica, tanto das pastas cerâmicas como das amostras de sedimento estudadas, tem sido realizada principalmente mediante difração de raios- $X$ (daqui em diante, $X R D$, pela sua sigla em inglês). AXRD consiste na determinação das fases cristalinas dos minerais presentes na amostra, mediante o uso de uma fonte incidente de raios- $X$, que, ao impactarem os elétrons dos átomos, sofrem um espalhamento coerente e permitem determinar a distância entre os planos ao interior do retículo cristalino (Artioli, 2010, pp. 50-52).

Tem-se utilizado a técnica de ressonância paramagnética eletrônica (daqui em diante, EPR, pela sua sigla em inglês), também conhecida como ressonância de spin eletrônico, para determinação da temperatura de queima da cerâmica. A técnica de EPR baseia-se num princípio analítico que envolve a medida da absorção de radiação de microondas por espécies paramagnéticas, materiais com pares de elétrons desemparelhados (Bensimon et al., 1998). Em termos gerais, o método mede a energia necessária para alinhar spins (movimentos dos elétrons) de espécies paramagnéticas sob a influência de um campo magnético externo. No caso da cerâmica, mede-se a alteração do $\mathrm{Fe}^{+3}$ submetido a diferentes temperaturas, para determinar a faixa requerida para alterar o espectro, que será a faixa na qual foi inicialmente queimada a cerâmica.

Por fim, entre as técnicas empregadas nas pesquisas do grupo, a datação por termoluminiscência (daqui em diante, TL) dos fragmentos cerâmicos tem ocupado também um lugar de destaque. $O$ princípio analítico da $T L$ reside na acumulação de defeitos nos grãos de quartzo da cerâmica, pelas radiações ionizantes do ambiente deposicional, no qual sofrem transferência de elétrons entre níveis e, assim, deixam lacunas que permanecem na nova posição por milhares de anos. Os grãos de quartzo são aquecidos no laboratório para estimular a recombinação de elétrons e lacunas, 'zerando o relógio' e medindo a luz emitida no processo (Tudela et al., 2012; Cano et al., 2015).

\section{A MATEMÁTICA ENVOLVIDA: BREVE DESCRIÇÃO}

Grande ênfase ao tratamento matemático foi feito pelo grupo, ao longo da sua história, com o escopo de obter dados confiáveis. A inspeção realizada por meio de procedimentos matemáticos começa com um controle de qualidade analítico, onde os dados obtidos para as amostras do material de referência de ampla distribuição (RM) são estudados para determinar quais das variáveis (elementos) medidas na cerâmica ou no sedimento do sítio devem ser preservadas

\footnotetext{
3 Ver Glascock e Neff (2003) e Munita et al. (2019).

4 Ver a seção "A matemática envolvida: breve descrição", neste artigo.
} 
e quais seriam descartadas. Trata-se do estudo da precisão e da exatidão analíticas (Bishop et al., 1990), já referidas.

Uma inspeção inicial dos outliers - ou valores anômalos devidos à não homogeneidade da amostra, contaminação, erros na medida etc. - é realizada mediante diferentes testes, após a transformação dos dados $^{5}$. Diversos trabalhos realizados com matemáticos têm submetido as bases de dados a distintos cálculos de distância (e.g. distância de Mahalanobis) ${ }^{6}$, a fim de se determinar o método mais robusto. A seguir, é realizada uma análise de conglomerados (cluster analysis) com o propósito de classificar, em um dendrograma, as amostras dentro dos grupos e entre grupos e de estabelecer a distância entre elas para formá-los. Os diferentes métodos hierárquicos de análises de agrupamentos também têm sido submetidos a testes com bases de dados cerâmicos (Carvalho, 2018). Os grupos composicionais detectados nos dendrogramas são depois explorados a partir da extração de um novo conjunto de variáveis, mediante análise discriminante canônica, o qual gera um gráfico com funções discriminantes para um nível de confiança determinado. O grupo tem utilizado também a análise de componentes principais (PCA, por sua sigla em inglês) e as redes neurais artificiais, que visualizam as diferenças em estruturas bi- ou tridimensionais, mediante construção de mapas de nós (ou neurônios) ${ }^{7}$.

Tanto no caso das técnicas analíticas quanto no das estatísticas, o/a leitor/a é convidado/a ao contato com as referências indicadas para sua maior informação.

\section{ASPECTOS DAS CADEIAS OPERATÓRIAS DAS CERÂMICAS E SEU POTENCIAL INFORMATIVO EM DIFERENTES CONTEXTOS}

Desde os já mencionados trabalhos iniciais do grupo (Munita et al., 1997, 2000a, 2000b), a ênfase esteve colocada na compreensão, por meio de técnicas físico-químicas, de alguns aspectos que fazem parte da organização das cadeias operatórias da confecção de cerâmicas. Por cadeia operatória, entende-se uma série de operações por meio das quais a matéria é transformada (Lemonnier, 1992, p. 26), e que, por sua vez, são constitutivas de procedimentos e de escolhas tecnológicas dentro de um contexto cultural (F. Silva, 2000, pp. 22-24).

grupo tem abordado três aspectos das cadeias operatórias das cerâmicas:

a) Proveniência da matéria-prima: em arqueologia, a proveniência designa a origem natural ou a fonte de um artefato (Glascock et al., 2007), e é apenas um aspecto a constituir o mais abrangente estudo da obtenção ou aprovisionamento de matérias-primas, o qual envolve a compreensão do modo em que as populações extraíram, transportaram e processaram inicialmente o material (Schiffer \& Skibo, 1997, pp. 35-37; Michelaki et al., 2015). Em termos geoquímicos ou arqueométricos, a proveniência refere-se ao denominado postulado de proveniência (Glascock \& Neff, 2003, p. 1521), que estabelece que a fonte de matéria-prima de um artefato pode ser determinada sempre que as diferenças químicas interfontes sejam maiores do que as intrafontes. No caso da cerâmica, devido à ampla distribuição dos afloramentos de argila, a aproximação corrente consiste em determinar grupos composicionais de referência nos fragmentos cerâmicos, para depois compará-los com amostras de fontes. $\bigcirc$ grupo tem desenvolvido essa estratégia, realizando o estudo multielementar tanto de fragmentos cerâmicos, quanto em alguns casos de amostras de argila de afloramentos conhecidos, mediante INAA e também com ajuda dos procedimentos de análise multivariada, referidos na seção anterior (Munita et al., 2005; Nunes, 2009; Santos et al., 2009; Nunes et al., 2013; Hazenfratz, 2014);

b) Composição da pasta: em termos de pasta (componentes), a cerâmica está constituída por uma matriz

\footnotetext{
5 Ver discussão em Santos et al. (2017) e Nogueira e Munita (2019).

6 Ver Oliveira \& Munita (2003) e Oliveira et al. (2010).

Ver detalhes em Hazenfratz et al. (2018).
}

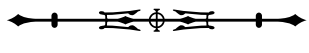


de argila, com inclusões de natureza diversa (mineral, vegetal, biomineral e partículas antropogênicas como fragmentos cerâmicos moídos), que recebem o nome de antiplástico ou tempero, além de diversos produtos de transformação mineralógica devidos à queima (Rice, 1987; ver também Barreto et al., 2016, pp. 553-568). A estratégia utilizada pelo grupo tem consistido em caracterizar as pastas cerâmicas mediante o estudo de amostras específicas referentes ao interior dos grupos composicionais multielementares (os mesmos utilizados para análise de proveniência), para conhecer a contribuição mineralógica relativa às diferenças detectadas entre os referidos grupos. A técnica mais utilizada, nesse caso, tem sido a $\mathrm{XRD}$, principalmente no que tange o estabelecimento da mineralogia das argilas empregadas, mas também foram usadas outras técnicas ocasionais, como o microscópio eletrônico de varredura (SEM, pela sua sigla em inglês) e a calorimetria de varredura diferencial (Santos et al., 2009);

c) Temperatura de queima: a queima é o processo por meio do qual o vasilhame é exposto ao fogo, sendo endurecida a cerâmica e retirada a umidade da pasta (Rice, 1987; Barreto et al., 2016, p. 565). Além da análise macroscópica, realizada mediante à observação do núcleo e da coloração da superfície da cerâmica, o estudo das diferentes faixas de temperatura às quais são submetidas as vasilhas cerâmicas durante a exposição ao fogo pode ser indicativo, em parte, de uma importante escolha tecnológica durante o processo de confecção da cerâmica (Rice, 1987). A presença de determinados minerais argilosos, estudados por meio de XRD, tem sido utilizada pelo grupo como indicador de transições de fases cristalográficas que ocorrem em temperaturas específicas, por exemplo, a caulinita assinala temperaturas de queima inferiores a 550-600 ${ }^{\circ} \mathrm{C}$ (Maggetti, 1982). Entretanto, a principal técnica empregada tem sido a EPR, que permite diferenciar faixas de temperatura.

É bom ressaltar que, além de aportar dados para a análise desses aspectos sobre cadeias operatórias das cerâmicas e as respectivas características tecnológicas da sua confecção, o grupo promove estas e outras técnicas para levantar diversas hipóteses sobre as diferentes ocupações culturais dos sítios pesquisados. Nesse sentido, os grupos composicionais multielementares cerâmicos, quando analisados de forma interdisciplinar, em relação aos dados tecnológicos e contextuais, podem informar sobre distintos materiais utilizados de forma recorrente ao longo do tempo pelos mesmos grupos ou ocupantes dos sítios, ou mesmo sobre o uso compartilhado de materiais por parte de diferentes grupos ou ocupantes. Esses dados podem oferecer subsídios para a compreensão das relações socioculturais, incluindo redes de troca e sistemas de alianças (Earle, 2009; Neves et al., 2019).

A seguir, são apresentados, de forma sintética, os principais resultados das análises arqueométricas cerâmicas realizadas pelo grupo, segundo as principais regiões estudadas: o Sudeste e o Nordeste do Brasil, a Amazônia e os contextos internacionais.

\section{AS CERÂMICAS DO SUDESTE BRASILEIRO}

Como fora mencionado na seção "Primeiras pesquisas e técnicas utilizadas pelo grupo", os primeiros estudos do grupo abordaram cerâmicas de sítios do Sudeste brasileiro, pesquisados sob coordenação da arqueóloga Márcia Angelina Alves, do MAE/USP, desde a década de 1980. No caso dos sítios Rezende e Prado, localizados no vale do alto rio Paranaíba e no Triângulo Mineiro, fazem parte de um amplo conjunto de sítios a céu aberto, sendo o primeiro o mais antigo da região, com ocupações précerâmicas que recuam até ca. 7.300 AP e ceramistas por volta dos 460 AP, e o segundo com ocupações ceramistas por volta dos 400 AP (e.g. Alves, 1992, 2002; Goulart et al., 2005). Por outro lado, o sítio Água Limpa, localizado no norte paulista, consiste num assentamento ceramista ocupado ca. 1.524 AP, com estruturas habitacionais e um vasto registro cerâmico, lítico, arqueofaunístico e de sepultamentos humanos (Alves \& Calleff, 1996).

O estudo realizado mediante INAA detectou grupos composicionais únicos no sítio Prado (Munita et al., 2000a), 
no sítio Rezende (Munita et al., 2001a) e no sítio Água Limpa (Munita et al., 2000b), o que foi confirmado em estudos comparativos posteriores (Munita et al., 2003) e permitiu formular a hipótese sobre o uso de uma única fonte de argila em cada um dos sítios ao longo das distintas ocupações. No caso do sítio Prado, um estudo posterior (Goulart et al., 2005), realizado por meio de petrografia, SEM e XRD, confirmou a semelhança entre as cerâmicas em termos microestruturais, com alta frequência de inclusões clásticas muito angulosas e mal selecionadas, que não apontaram para uma adição intencional, mas sim para sua ocorrência natural na fonte, algo que foi confirmado em duas amostras locais pelos autores.

\section{AS CERÂMICAS DO NORDESTE BRASILEIRO}

A colaboração do grupo com arqueólogos/as da região nordestina teve origem no começo do presente século, com o estudo de cerâmicas dos diferentes sítios da região de Xingó, no baixo rio São Francisco (estados de Sergipe e Alagoas) e de um sítio próximo à região (Alcobaça, no estado de Pernambuco). Esses sítios foram reconhecidos e abordados inicialmente pelo "Projeto Arqueológico de Xingó (PAX)" numa área afetada pela Unidade Hidrelétrica de Xingó. No âmbito de uma colaboração com as Profas Suely Luna e Ana Nascimento, da Universidade Federal de Pernambuco, foram estudados artefatos das diferentes ocupações ceramistas regionais, as quais apresentaram idades radiocarbônicas que recuam até pelo menos 5.570 AP (sítio Justino) e que evidenciam diferentes dinâmicas de assentamentos em aldeias ou sítios habitação/ cemitérios e acampamentos ${ }^{8}$.

As análises por INAA das amostras pertencentes aos seis sítios estudados permitiram determinar a existência de um único grupo composicional nas argilas utilizadas na confecção das vasilhas (Munita et al., 2004).
Esses resultados permitiram levantar hipóteses não apenas sobre uma possível proveniência comum da matéria-prima empregada pelos diferentes grupos ocupantes dos sítios, mas também sobre as possíveis escolhas tecnológicas compartilhadas desses materiais, ao longo do tempo.

Outra contribuição ao estudo das cerâmicas do baixo São Francisco foi desenvolvida por Santos (2007), na sua tese de doutorado, em colaboração com a arqueóloga Profa Maria C. Z. Vergne. O autor estudou fragmentos cerâmicos de alguns dos sítios abordados por Munita et al. (2004) (Justino, São José I e Vitória Régia I), e de outros cinco sítios também reconhecidos pelo PAX(Santos, 2007, pp. 21-24). Santos (2007) comparou, mediante INAA, dois cemitérios do sítio Justino (o cemitério B e o C), encontrando diferenças significativas na sua composição elementar'; outras comparações permitiram ver diferenças entre os sítios cemitério B de Justino e São José (ocupações antigas e próximas), semelhanças entre Porto Belo, Saco da Onça, Vitória Régia e Curituba (ocupações recentes), e diferenças entre Justino, Porto Belo e Curituba (ocupações antigas e recentes). $\mathrm{O}$ autor interpretou as diferenças internas às ocupações antigas do Justino e do São José como derivadas de escolhas tecnológicas ${ }^{10}$, sendo que os outros resultados foram reconhecidos como frutos de mudanças cronológicas. $O$ estudo mineralógico (XRD) determinou composições comuns em todos os sítios, com algumas diferenças em São José e Justino, que apresentaram caulinita em algumas fases de ocupação. Depois de realizadas as datações mediante TL, o autor confirmou a antiguidade do sítio Justino, além de aportar dados para fases específicas dos sítios estudados ${ }^{11}$.

Um estudo mais recente com foco na região nordestina foi realizado com material cerâmico proveniente do sítio Capim, localizado na região da Chapada do Araripe, município de Araripina, estado de Pernambuco,

\footnotetext{
8 Sobre este assunto, ver Luna (2005) e Almeida e Kater (2017).

9 Ver também Santos et al. (2008).

10 Ver também Santos et al. (2006).

11 Ver também Vergne (2004).
} 
em colaboração com arqueólogos/as da Universidade Federal de Pernambuco e da Universidade Federal do Vale do São Francisco (Munita et al., 2018). O sítio Capim foi alvo de coletas sistemáticas feitas na década de 1980 e de estudos mais recentes, no âmbito da compreensão das ocupações relacionadas com a tradição Tupiguarani no Nordeste (Maranca \& Meggers, 1980; Leite Neto, 2008; Amaral, 2015). A abordagem arqueométrica, por meio do estudo multielementar de fragmentos de borda coletados em cinco das seis concentrações artefatuais documentadas no sítio, teve o intuito de explorar uma possível relação entre os conjuntos de vasilhames e diferentes fontes de matéria-prima utilizadas pelos ocupantes. Os três grupos composicionais obtidos permitiram lançar hipóteses sobre diferentes cenários de deslocamento para três pontos de coleta de argilas, segundo a possível contemporaneidade ou não dos conjuntos analisados, que deverão ser testados com outros estudos (Munita et al., 2018, pp. 186-187).

\section{A AMAZÔNIA: A PROVENIÊNCIA E O PROBLEMA DAS REDES DE TROCA}

O problema da proveniência das argilas que foram usadas para produzir as cerâmicas que integram o registro arqueológico também motivou o desenvolvimento de estudos arqueométricos por parte de integrantes do grupo na Amazônia. A bacia amazônica constitui uma das áreas de maior importância em termos de diversidade biológica, cultural e linguística do planeta, contendo expressivos testemunhos arqueológicos de distintos grupos humanos ao longo do tempo, materializadas em terras pretas de índio (solos antropogênicos), montículos, sambaquis, geoglifos, megálitos, florestas culturais, campos elevados e arte rupestre ${ }^{12}$. A cerâmica é a classe de vestígio arqueológico mais abundante na Amazônia, e aí tem residido não só a importância no mapeamento da sua diversidade cultural, mas também o caráter informativo sobre processos e escolhas tecnológicas dos/as artesãos/ãs, que contribuíram com suas ações à impressão material das identidades regionais (Lima et al., 2016).

A etnoarqueologia, o estudo etnográfico das comunidades atuais para a leitura do passado documentado no registro arqueológico, tem sido uma das ferramentas utilizadas para a compreensão dos diferentes aspectos imbuídos na relação entre as pessoas e o material cerâmico na arqueologia amazônica (F. Silva, 2000, 2016). Entre os múltiplos aspectos do olhar etnoarqueológico sobre a cerâmica, a variabilidade nos atributos ou a variabilidade formal ocupa um lugar de destaque na hora de se compreender processos produtivos pretéritos, entre eles está a composição da pasta e a sua relação com o uso das fontes de argila (F. Silva, 2016, p. 42). A

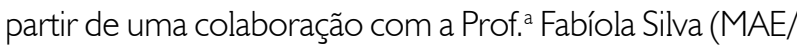
USP), Munita et al. (2005) abordaram amostras de dois depósitos de argila, utilizados pelas ceramistas Asurini do Xingu (Terra Indígena Koatinemo), comunidade do leste da Amazônia, aos efeitos de determinar se as diferenças entre preferências conhecidas de determinadas fontes seriam detectáveis por meio de análises arqueométricas. Mediante uma comparação com INAA dos depósitos A e B com fragmentos de cerâmicas produzidas com uma dessas fontes (A), foi confirmada a proveniência da fonte conhecida, a qual também foi diferenciada por meio de observações mineralógicas e de fábrica com microscópio eletrônico de varredura (MEV). Tal discriminação, que não apresentava grandes diferenças em termos macroscópicos, mas que era percebida pelas artesãs na 'performance' das argilas (i.e., relacionada a determinados desempenhos dos artefatos ${ }^{13}$, confirmou a importância de pesquisas arqueométricas e petrográficas no estudo da proveniência dos critérios técnicos usados nas cerâmicas arqueológicas.

A colaboração com arqueólogos/as que trabalham na região amazônica teve outro impulso no sentido da

\footnotetext{
12 Ver capítulos em Rostain e Betancourt (2017); ver também Heckenberger e Neves (2009) e Neves (2011).

13 Ver Schiffer e Skibo (1997, pp. 30-31).
}

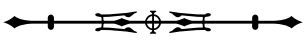


compreensão da proveniência e de alguns aspectos tecnológicos de cerâmicas da ilha de Marajó, na foz do rio Amazonas, região nordeste do estado de Pará (Toyota, 2009; Munita et al., 2011). Na sua dissertação de mestrado, Toyota (2009) comparou composições elementares de fragmentos cerâmicos recuperados em diferentes sítios da ilha de Marajó, procedentes tanto das pesquisas realizadas pela então Profa. Denise P. Schaan (Universidade Federal do Pará), como de coleções do acervo do MAE/USP (coletadas na década de 1950), em colaboração com o Prof. Eduardo Góes Neves e com a Dra. Cristina Demartini. Após realizar o estudo das amostras do acervo do MAE/ USP, provenientes dos sítios Furinho, Cuieiras, Pacoval dos Mello, Pacoval e Fazenda São Marcos, Toyota (2009) determinou a presença de dois grupos composicionais diferentes. A autora analisou, a seguir, as amostras coletadas nas pesquisas desenvolvidas por Schaan (2004) nos sítios Guariba, Santa Fé 1 e 2, Parapará, Enseada, Mãe Rita 1, Pacoval, Guajará e Ilha do Fogo, e determinou que a maioria das amostras pertencia aos mesmos dois grupos composicionais detectados para as cerâmicas coletadas na década de 1950 (Toyota, 2009, pp. 65-67). A hipótese levantada pela autora, e posteriormente mantida por Munita et al. (2011), foi de que, na manufatura das cerâmicas dos diferentes períodos e áreas da ilha de Marajó, foram utilizadas, principalmente, duas fontes de argila.

Outro desenvolvimento importante do estudo de Toyota (2009) foi a comparação das amostras arqueológicas com amostras de réplicas atuais de cerâmicas arqueológicas produzidas por artesãos da ilha. $O$ intuito era o de se determinar o potencial das técnicas arqueométricas (em particular, a INAA) para caracterizar e distinguir as amostras passadas e recentes em eventuais casos de peças arqueológicas suspeitas de terem sido sujeitas ao comércio ilegal. As análises confirmaram as expectativas (Toyota, 2009, pp. 67-68; Munita et al., 2011, pp. 140-145), demonstrando a presença de um grupo composicional contemporâneo, diferente do grupo das amostras arqueológicas, indicando o uso atual de uma fonte de matéria-prima distinta das duas exploradas pelas populações pré-cabralianas.

Os estudos do grupo com arqueólogos/as que pesquisam a bacia amazônica tiveram outro importante âmbito contextual na região da Amazônia Central. Tratase de um vasto território de cerca de $900 \mathrm{~km}^{2}$, irrigado e delimitado pelas bacias dos rios Solimões, Negro e Ariaú, abordado e posteriormente ampliado, desde 1995, pelo "Projeto Amazônia Central (PAC)", sob coordenação dos Prof. Eduardo Góes Neves, Michael Heckenberger e James Petersen (Heckenberger et al., 1999; Neves et al., 2004; Neves \& Petersen, 2006). Nessa ampla região de transição entre ecossistemas de águas negras e águas claras, entre terra firme e várzea, confluíram diversas culturas, reconhecidas a partir de distintas fases arqueológicas, com base em atributos cerâmicos desde ca. 2.500 AP (há também ocupações précerâmicas), como também em extensas modificações da paisagem sob a forma de terras pretas, montículos e valas (Neves \& Petersen, 2006; Lima, 2008; Neves, 2011).

Na Amazônia Central, os estudos arqueométricos do grupo estiveram dirigidos tanto à compreensão de diferenças composicionais ao interior de sítios específicos, quanto à comparação de diferentes sítios arqueológicos num olhar regional. No primeiro caso, têm-se os trabalhos sobre os sítios Hatahara e São Paulo II, ambos localizados no estado de Amazonas, nos municípios de Iranduba e Coari, respectivamente. No segundo caso, situam-se as pesquisas que compararam os sítios Lago Grande e Osvaldo, também localizados no mencionado município de Iranduba.

O sítio Hatahara, localizado num barranco na margem esquerda do rio Solimões, apresentou uma longa história indígena de ocupações que deixaram extensas acumulações de cerâmica, terra preta e montículos (alguns com sepultamentos), recebendo, desde ca. 2.250 AP, o aporte cultural reconhecido nas fases Açutuba, Manacapuru e Paredão, da Tradição Borda Incisa, e a fase ou subtradição Guarita, da Tradição Polícroma da Amazônia (Neves et al., 2004; Machado, 2005; Rebellato et al., 2009; Tamanaha \& Py-Daniel, 2009). 
Com uma amostragem de 120 fragmentos cerâmicos recuperados no sítio e atribuídos macroscopicamente às fases Manacapuru, Paredão e Guarita, Nunes (2009) identificou cinco grupos composicionais nas pastas, sendo três deles correspondentes a fases únicas (dois Manacapuru e um Paredão) e os outros dois apresentando material das três fases. Enquanto que as diferenças entre grupos da fase Manacapuru foram correlacionadas com diferenças decorativas ao interior da fase percebidas no sítio, a pertença dos grupos de fases múltiplas permitiu formular a hipótese do uso de uma mesma fonte de matéria-prima, pelo menos em alguns momentos das diferentes ocupações (Nunes, 2009; Nunes et al., 2010, pp. 65-70, Nunes et al., 2013). A comparação com amostras de argila coletadas a 6 km do sítio (Nunes, 2009, pp. 57-58; Nunes et al., 2013) permitiu corroborar, num grupo composicional, a existência da referida fonte compartilhada pelas três fases. Por sua parte, a análise da temperatura de queima mediante EPR não revelou diferenças entre as fases.

O sítio São Paulo II, por sua parte, localizado numa área de várzea entre igarapés próxima à calha do médiobaixo rio Solimões, consiste num sítio unicomponencial com material cerâmico da fase Guarita, da Tradição Polícroma da Amazônia (Tamanaha, 2012, 2016). A abordagem arqueométrica desenvolvida por Baria (2013; Baria et al., 2015) determinou a presença de três grupos multielementares nas cerâmicas do sítio, os quais apresentaram a mesma faixa de temperatura de queima, e foram datados por meio de TL em ca. 845-1.184 d.C (Cano et al., 2015), oferecendo mais dados para a compreensão do panorama regional conhecido das ocupações polícromas na região (Tamanaha, 2012, 2016).

No caso dos sítios Lago Grande e Osvaldo, localizados em terrenos altos próximos à várzea do rio Solimões, distantes $9 \mathrm{~km}$ entre si e conectados por uma rede de canais fluviais (Neves et al., 2004), o intuito das pesquisas arqueométricas, desenvolvidas por
Hazenfratz (2014) e equipe (Hazenfratz et al., 2012, 2016, 2018; Neves et al., 2019), foi o de contribuir para a compreensão de um sistema de interações regionais culturais da Amazônia Central. A existência de diversas esferas de interação amazônicas sob a forma de alianças interétnicas, rituais, casamentos exogâmicos, redes de troca ou comércio, entre outras, que foram observadas na região pelos primeiros exploradores europeus, teve nos sítios Lago Grande e Osvaldo a possibilidade de um correlato arqueológico nos dados da análise cerâmica (Donatti, 2003; Portocarrero, 2007; Lima, 2008; Mongeló, 2011). Assim, enquanto no primeiro e no segundo predominam cerâmicas das fases Paredão e Manacapuru, respectivamente, ambos os sítios apresentaram também material da fase predominante no outro sítio, além de material com características 'híbridas' (Portocarrero, 2007; Mongeló, 2011, p. 112). Apesar de possuírem características diferenciadoras, as duas fases pertencem à Tradição Borda Incisa ou Barrancoide, com bordas largas achatadas no topo e decoradas com incisões e uso de cauixi (esponja de água doce) como tempero principal, entre outras, e que se insere nas discussões sobre a expansão dos grupos falantes de línguas Arawak ${ }^{14}$.

As análises desenvolvidas por Hazenfratz (2014) e Hazenfratz et al. (2012, 2016, 2018), com base numa amostragem de 200 fragmentos cerâmicos classificados tanto numa fase quanto na outra nos dois sítios arqueológicos, evidenciaram (em múltiplos cenários estudados mediante PCA e redes neurais) a presença de dois grandes grupos composicionais multielementares ao interior de cada sítio com um importante grau de superposição, revelando o complexo panorama esperado. Análises elementares de amostras de cauixi coletadas nas proximidades dos sítios, e de inclusões de cauixi separadas de fragmentos cerâmicos, permitiram descartar o efeito da diluição desse tempero no enriquecimento de alguns elementos. O autor comparou depois os dois sítios (Hazenfratz, 2014, pp. 257-275;

\footnotetext{
14 Para mais detalhes e discussões, ver Lima (2008), Lima e Neves (2011) e Neves et al. (2019).
} 
Hazenfratz et al., 2016), obtendo também uma superposição entre dois grupos, equivalentes com os grupos superpostos identificados em cada sítio. A conformação dos grupos dos dois sítios com material das fases Manacapuru e Paredão, junto com observações tecnológicas realizadas pelos/as arqueólogos/as previamente, permitiu manter a hipótese de uma rede de interações entre os sítios, refletida num uso comum de diferentes fontes de matérias-primas ou de conhecimentos tecnológicos compartilhados (Neves et al., 2019).

De maneira mais recente, o grupo tem trabalhado com problemáticas arqueológicas do sudoeste da Amazônia, uma vasta região compreendida pela bacia do rio Madeira, incluindo parte do leste boliviano e dos estados brasileiros de Rondônia e Acre, e caracterizada pela diversidade de ambientes entre as savanas alagadas sazonalmente dos Llanos de Moxos bolivianos e as florestas de bambu do Acre. Tendo como referências fundamentais, no lado brasileiro, os trabalhos de Eurico Miller e de Ondemar Dias (no caso do Acre), desde a década de 1970, as pesquisas na região vêm se intensificando nas últimas décadas, mostrando um complexo (e em alguns setores, muito antigo) mosaico cultural de longa duração, que inclui transformações da paisagem como terras pretas, geoglifos, montículos e sambaquis (e.g. Almeida, 2013; Pessoa, 2015; Zimpel \& Pugliese Jr., 2016; Zuse, 2016; Almeida \& Kater, 2017; A. Costa \& Gomes, 2018; Furquim, 2018; Pugliese Jr., 2018; Saunaluoma et al., 2018), além de evidências recuadas de produção de alimentos (Watling et al., 2018).

Aárea do médio rio Guaporé, na fronteira entre Brasil e Bolívia, é um dos importantes enclaves arqueológicos do sudoeste amazônico, com ocupações que recuam mais de 9.500 anos, e uma grande diversidade cultural (Zimpel \& Pugliese Jr., 2016). Nesse contexto, situa-se o sítio Monte Castelo (município de São Francisco do Guaporé, estado de Rondônia), um sambaqui (sítio monticular que apresenta uma matriz predominantemente constituída por conchas de moluscos) que se destaca na paisagem de banhados da região e apresenta um vasto e contínuo registro arqueológico formado ao longo do tempo, com presença de material lítico, cerâmico, arqueofaunístico, macro e microvestígios botânicos e sepultamentos humanos ${ }^{15}$. A fase Bacabal, detectada no sambaqui a partir de ca. 4.200 AP, está constituída por uma cerâmica com cauixi como principal tempero e decorações plásticas que incluem excisões e incisões, entre outros. A caracterização físico-química dessa cerâmica foi realizada por Carvalho (2019), no âmbito da sua tese de doutorado, com o intuito de oferecer novos dados sobre a composição das pastas e novas idades, mediante TL, para a fase Bacabal. Os três grupos multielementares identificados na cerâmica foram associados, por meio da datação por TL, a três períodos diferentes com congruência estratigráfica, com idades máximas entre ca. 3.458 (grupo 1) e ca. 1.377 (grupo 3), que indicaram um uso diferenciado de fontes de argila em três momentos, e confirmaram a antiguidade e persistência das ocupações relacionadas à fase Bacabal (Carvalho, 2019; Carvalho et al., 2019).

Outra região que vem sendo amplamente estudada nos últimos anos dentro do sudoeste amazônico é a compreendida pela bacia do alto rio Madeira, tanto no âmbito de pesquisas acadêmicas como de trabalhos de licenciamento ambiental, com implicâncias para a discussão sobre relações culturais de longa duração, rituais funerários envolvendo comensalidade, origem das terras pretas amazônicas, início da produção de alimentos, entre outros (e.g. Almeida, 2013; Pessoa, 2015; Zuse, 2016; Almeida \& Kater, 2017; A. Costa \& Gomes, 2018; Watling et al., 2018). Os primeiros estudos de INAA para essa região vêm sendo realizados por Angislaine Costa, a partir de amostragem de fragmentos cerâmicos procedentes de oito sítios arqueológicos, localizados tanto em ilhas fluviais quanto na beira do alto rio Madeira. $\bigcirc$ objetivo é aportar dados à compreensão das interações culturais e do uso de fontes de matéria-prima por diferentes povos que coabitaram o mesmo espaço geográfico, por volta de 1.000 AP.

\footnotetext{
${ }^{15}$ Ver Furquim (2018) e Pugliese Jr. (2018).
}

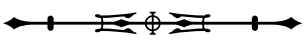


Resultados iniciais (A. Costa et al., 2019) indicaram a presença de quatro grupos composicionais. A continuação da pesquisa (ainda em andamento) permitirá desvendar se essas diferenças de composição química das argilas correspondem a diferentes escolhas, relacionadas a tradições culturais distintas, ou se existe uma diversidade de escolhas dentro de uma mesma tradição. Uma terceira problemática é se estas mesmas fontes podem ter sido acessadas ao longo do tempo e contemporaneamente por distintas populações, com possibilidade de intercâmbios de matérias-primas e artefatos, ajudando a compreender o complexo panorama apresentado e sua relação com as ocupações regionais.

\section{CERÂMICAS EM CONTEXTOS INTERNACIONAIS}

O grupo vem analisando, nos últimos anos, cerâmicas provenientes de contextos internacionais. Vem-se desenvolvendo estudos de arqueometria com cerâmicas arqueológicas do Oriente Próximo, em colaboração com o arqueólogo Rodrigo da Silva, do Centro Universitário Adventista de São Paulo, no Brasil. Num estudo que mostra a utilidade das técnicas empregadas para responder perguntas arqueológicas específicas, R. Silva et al. (2017) analisaram um tijolo de terracota com uma inscrição em caracteres cuneiformes que estudos tipológicos e outros relacionavam com a dinastia de Nabucodonosor II, monarca do Império Neo-Babilônico (séculos VI-VII a.C.). As análises de XRD e de EPR evidenciaram temperaturas de queima inferiores a $400^{\circ} \mathrm{C}$, o que permitiu pensar na ausência de queima real do tijolo, de acordo com a literatura sobre o período. A análise por TL deu uma idade de ca. 2.350 anos, que, segundo os autores, permite relacionar a amostra com outras terracotas babilônicas presentes no acervo do Museu do Louvre, na França, e que corresponderia a um período de reconstrução de templos na cidade (R. Silva et al., 2017, p. 67).

Outro estudo com cerâmicas do Oriente Próximo vem sendo desenvolvido no sítio arqueológico de Jericó (atual Tell es-Sultan), na Palestina, também em parceria com Rodrigo da Silva. Sendo um dos sítios arqueológicos mais importantes do mundo, com ocupações desde ca. 11.000 AP, as cerâmicas estudadas por Joanna Barros correspondem à Idade do Bronze Tardio, e os resultados, ainda preliminares, indicaram a presença de três grupos composicionais, cujo significado deverá ser explorado na continuação da pesquisa (Barros et al., 2019).

\section{A FORMAÇÃO DOS DEPÓSITOS ARQUEOLÓGICOS}

Uma contribuição mais recente na história do grupo visa explorar as características físico-químicas dos depósitos escavados em sítios arqueológicos, para aportar subsídios ao conhecimento dos processos de formação neles atuantes. A formação dos sítios é frequentemente o produto de uma complexa relação entre processos naturais (e.g., fluxo de detritos, transporte fluvial) e atividades e processos humanos (e.g., formação de montículos, estruturas de combustão etc.) que depositam materiais de origem humana e não humana, sendo afetados ao longo do tempo por dinâmicas pósdeposicionais de índole diversa (Karkanas \& Goldberg, 2018). As técnicas analíticas multielementares e as moleculares são algumas das abordagens hoje utilizadas, nos estudos geoarqueológicos, para a compreensão dos aportes naturais e antropogênicos nos sítios.

Nessa linha de estudos, a primeira abordagem desenvolvida no grupo foi o trabalho de Tudela (2013), com amostras de sedimento do sítio Lapa Grande de Taquaraçu (daqui em diante, LGT), no município de Jaboticatubas, estado de Minas Gerais. Trata-se de um dos sítios que se insere nas discussões sobre o povoamento inicial do Sudeste e do Centro do Brasil, com datas que recuam até ca. 9.990 AP, e que está associado em termos de dinâmicas culturais à área de Lagoa Santa, uma das regiões arqueológicas mais importantes do continente ${ }^{16}$. Estudos geoarqueológicos na região, desenvolvidos

\footnotetext{
16 Ver capítulos em Da-Gloria et al. (2017).
}

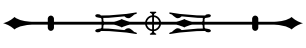


desde a década passada, vêm evidenciando uma intensa contribuição antropogênica nos depósitos dos sítios em abrigos sob rocha, sob a forma de cinzas calcíticas de plantas empregadas na combustão, entre outras (e.g. Araujo et al., 2008; L. Silva, 2013; Villagran et al., 2017).

O intuito de Tudela (2013) foi o de caracterizar tal aporte antropogênico em LGT do ponto de vista multielementar e mineralógico, em colaboração com o coordenador das escavações, o Prof. Astolfo Araujo. Com amostras de sedimento de diferentes profundidades coletadas em quatro das sete quadras escavadas, Tudela (2013) determinou a presença de três grupos multielementares distintos, com uma separação estratigráfica em dois dos casos; os dados composicionais e as observações realizadas no sítio pelos escavadores levaram o autor a relacionar o primeiro grupo (sedimentos pulverulentos acinzentados) com uma contribuição predominantemente antropogênica, um segundo grupo com valores intermédios e o terceiro (sedimentos avermelhados) basicamente geogênico. Análises mineralógicas por meio de XRD evidenciaram uma alta presença de calcita e de quartzo no primeiro e terceiro grupo respectivamente, permitindo manter a hipótese de uma contribuição humana devido à presença de cinzas calcíticas, produto da queima de plantas versus aportes naturais, conformados por sedimentos fluviais arenosos e solo dos arredores retrabalhado. $O$ autor reconheceu a necessidade de mais estudos para contrastar as hipóteses levantadas (Tudela, 2013, p. 78), existindo também outras abordagens sobre os depósitos do sítio (L. Silva, 2013; Endo, 2017).

\section{CONCLUSÕES: A CONTRIBUIÇÃO DO GRUPO PARA AS HISTÓRIAS SOCIOCULTURAIS E FORMATIVAS DOS CONTEXTOS ARQUEOLÓGICOS}

Por mais de 20 anos, o Grupo de Estudos Arqueométricos do IPEN-CNEN/SP tem contribuído à interface entre arqueologia e estudos físico-químicos e matemáticos, denominada comumente de arqueometria. Tendo como base a análise composicional multielementar por meio de
INAA, desenvolvida no reator de pesquisas do IPEN, e com uma forte ênfase na avaliação estatística dos dados, o grupo foi cultivando ao longo desses anos diferentes colaborações com arqueólogos/as e especialistas em diversas outras técnicas físico-químicas (e.g. XRD, EPR, $\mathrm{TL}$ ), com o intuito comum de responder perguntas de cunho arqueológico. Entre elas, tem ocupado um lugar de destaque na produção do grupo a identificação da composição da pasta, da proveniência e da temperatura de queima das cerâmicas arqueológicas de diversas áreas do Brasil (o Sudeste, o Nordeste e a Amazônia) e do mundo (o Oriente Próximo).

Além de permitir pensar sobre diferenças nas fontes de argila utilizadas, os grupos composicionais identificados em um ou vários sítios arqueológicos serviram de base para levantar hipóteses sobre conhecimentos tecnológicos compartilhados, e as diferentes formas de interação social existentes em diversos períodos. Quando esses dados foram lidos interdisciplinarmente, em conjunção com as idades obtidas por $T L$ dos fragmentos cerâmicos e com as evidências tecnológicas e dos contextos escavados pelos/as arqueólogos/as, eles aportaram, como no caso do Sudeste, do Nordeste e de vários setores da bacia amazônica, à interpretação das histórias indígenas de longa duração, bem como das persistências e mudanças culturais. Em outros casos, os dados físico-químicos e a leitura contextual têm ajudado na resposta a perguntas arqueológicas concretas, como foi o caso do tijolo com inscrição cuneiforme.

A incorporação mais recente das análises multielementares e mineralógicas de amostras de sedimento vem contribuindo com a compreensão das histórias formativas dos sítios arqueológicos. A análise dos depósitos, em conjunção com o resto da evidência, aporta indícios sobre o papel dos humanos e não humanos nos sítios arqueológicos.

Por fim, os trabalhos realizados põem em destaque a importância da colaboração e do diálogo interdisciplinares para o desenvolvimento de um conhecimento integral sobre as diferentes sociedades, sua cultura material e o seu meio. 


\section{AGRADECIMENTOS}

Agradecemos às seguintes agências de fomento: 1) Fundação de Amparo à Pesquisa do Estado de São Paulo (FAPESP), processo 2018/14293-3, N. Batalla; 2) Coordenação de Aperfeiçoamento de Pessoal de Nível Superior (CAPES), processo 1591568/2016, A.F. Costa; 3) Comissão Nacional de Energia Nuclear (CNEN), J. F. Barros.

\section{REFERÊNCIAS}

Almeida, F. O. (2013). A Tradição Polícroma no Alto Rio Madeira (Tese de doutorado). Museu de Arqueologia e Etnologia, Universidade de São Paulo, São Paulo, SP, Brasil.

Almeida, F. O., \& Kater, T. (2017). As cachoeiras como bolsões de histórias dos grupos indígenas das terras baixas sul-americanas. Revista Brasileira de História, 37(75), 39-67. doi: https://doi. org/10.1590/1806-93472017v37n75-02a

Alves, M. A. (1992). As estruturas arqueológicas do alto Paranaíba e Triângulo Mineiro - Minas Gerais. Revista do Museu de Arqueologia e Etnologia, 2, 27-47. doi: https://doi.org/10.11606/ issn.2448-1750.revmae.1992.108991

Alves, M. A. (2002). O sítio Rezende: de acampamento de caçadores-coletores a aldeia ceramista pré-histórica. Revista Clio: Série Arqueológica, 1(15), 189-204.

Alves, M. A., \& Calleff, M. E. V. (1996). Sítio de Água Limpa, Monte Alto, São Paulo - estruturas de combustão, restos alimentares e padrões de subsistência. Revista do Museu de Arqueologia e Etnologia, 6, 123-140. doi: https://doi.org/10.11606/issn.24481750. revmae.1996.109256

Amaral, A. M. (2015). "Andanças" Tupiguarani na Chapada do Araripe: análises das correlações entre mobilidade humana, tecnologia cerâmica e recursos ambientais (Tese de doutorado). Universidade Federal de Pernambuco, Recife, PE, Brasil.

Appoloni, C. R. (2018). Estudos em arqueometria e arte por metodologias nuclear-atômico-moleculares não destrutivas no Laboratório de Física Nuclear Aplicada da Universidade Estadual de Londrina. Cadernos do LEPAARQ, 15(30), 219-228.

Araujo, A. G. M., Feathers, J. K., Arroyo-Kalin, M., \& Tizuka, M. M. (2008). Lapa das Boleiras rockshelter: stratigraphy and formation processes at a Paleoamerican site in Central Brazil. Journal of Archaeological Science, 35(12), 3186-3202. doi: https://doi.org/10.1016/j.jas.2008.07.007

Artioli, G. (2010). Scientific methods and cultural heritage: an introduction to the application of materials science to archaeometry and conservation science. New York: Oxford University Press.
Baria, R. (2013). Caracterização físico-química da cerâmica do sítio arqueológico São Paulo II (Dissertação de mestrado). Instituto de Pesquisas Energéticas e Nucleares, Universidade de São Paulo, São Paulo, SP, Brasil.

Baria, R., Cano, N. F., Silva-Carrera, B. N., Watanabe, S., Neves, E. G., Tatumi, S. H., \& Munita, C. S. (2015). Archaeometric studies of ceramics from the São Paulo II archaeological site. Journal of Radioanalytical and Nuclear Chemistry, 306(3), 721727. doi: https://doi.org/10.1007/s10967-015-4183-5

Barreto, C., Lima, H. P., \& Betancourt, C. J. (Orgs.). (2016). Cerâmicas arqueológicas da Amazônia: rumo a uma nova síntese. Belém: IPHAN.

Barros, J. F., Da Silva, R. P., \& Munita, C. S. (2019, outubro) Preliminary chemical studies at the Jericho archaeological site. In Annals of the International Nuclear Atlantic Conference INAC, Associação Brasileira de Energia Nuclear, Santos, Brasil.

Bellido, A. V., \& Latini, R. M. (2013). Cerâmicas arqueológicas brasileiras: uma revisão de estudos arqueométricos em sítios arqueológicos do Acre, bacia Amazônica e da Região dos Lagos, Rio de Janeiro. Geochimica Brasiliensis, 27(2), 140-151.

Bensimon, Y., Deroide, B., Clavel, S., \& Zanchetta, J.-V. (1998) Electron Spin Resonance and dilatometric studies of ancient ceramics applied to the determination of firing temperature. Japanese Journal of Applied Physics, 37(8), 4367-4372. doi: https://doi.org/10.1143/JJAP.37.4367

Bishop, R. L., Canouts, V., Crown, P. L., \& De Atley, S. P. (1990). Sensitivity, precision, and accuracy: their roles in ceramic compositional data bases. American Antiquity, 55(3), 537-546. doi: https://doi.org/10.2307/281283

Cano, N. F., Ribeiro, R. B., Munita, C. S., Watanabe, S., Neves, E. G., \& Tamanaha, E. K. (2015). Dating and determination of firing temperature of ancient potteries from São Paulo II archaeological site, Brazil by TL and EPR techniques. Journal of Cultural Heritage, 16(3), 361-364. doi: https://doi.org/10.1016/j. culher.2014.05.010

Carvalho, P. R. (2018). Estudo comparativo dos algoritmos hierárquicos de análise de agrupamentos em resultados experimentais (Dissertação de mestrado). Instituto de Pesquisas Energéticas e Nucleares, Universidade de São Paulo, São Paulo, SP, Brasil.

Carvalho, P. R. (2019). Cerâmicas arqueológicas e arqueometria. Fase Bacabal: um estudo sobre a ocupação no sudoeste da Amazônia (Tese de doutorado). Instituto de Pesquisas Energéticas e Nucleares, Universidade de São Paulo, São Paulo, SP, Brasil.

Carvalho, P. R., Munita, C. S., Neves, E. G., \& Zimpel, C. A. (2019). Chemical characterization of ancient pottery from the southwest Amazonia using Instrumental Neutron Activation Analysis. Brazilian Journal of Radiation Sciences, 7(2-A), 1-14. doi: https:// doi.org/10.15392/bjrs.v7i2A.619 
Costa, A. F., \& Gomes, D. M. C. (2018). A multifuncionalidade das vasilhas cerâmicas do alto rio Madeira (séculos X-XII d.C): comensalidade cotidiana e ritual. Revista de Antropologia da USP, 61(3), 52-85. doi: https://doi.org/10.11606/2179-0892. ra.2018.152040

Costa, A. F., Munita, C. S., Zuse, S., \& Kipnis, R. (2019, outubro). Archaeometryand archaeology: preliminary studies of the ceramics from archaeological sites of the upper Madeira river/Rondônia Brazil. In Annals of the International Nuclear Atlantic Conference - INAC, Associação Brasileira de Energia Nuclear, Santos, Brasil.

Costa, J. A., Kern, D. C., Costa, M. L., Rodrigues, T. E., Kämpf, N., Lehmann, J., \& Frazão, F. J. L. (2009). Geoquímica das Terras Pretas Amazônicas. In W. G. Teixeira, D. C. Kern, B. E. Madari, H. N. Lima \& W. Woods (Eds.), As Terras Pretas de Índio da Amazônia: sua caracterização e uso deste conhecimento na criação de novas áreas (pp. 162-171). Manaus: Embrapa Amazônia Ocidental.

Costa, M. L., Carmo, M. S., Oliveira, E. C., Lima, H., Kern, D. C., \& Goeske, J. (2009). A mineralogia e composição química de fragmentos de cerâmicas arqueológicas em sítios de Terra Preta de Índio. In W. G. Teixeira, D. C. Kern, B. E. Madari, H. N. Lima \& W. Woods (Eds.), As Terras Pretas de Índio da Amazônia: sua caracterização e uso deste conhecimento na criação de novas áreas (pp. 225-241). Manaus: Embrapa Amazônia Ocidental.

Da-Gloria, P., Neves, W. A., \& Hubbe, M. (Eds.). (2017). Archaeological and paleontological research in Lagoa Santa: the quest for the first Americans. Cham: Springer International Publishing.

Donatti, P. B. (2003). A ocupação pré-colonial da área do Lago Grande, Iranduba, AM (Dissertação de mestrado). Faculdade de Filosofia, Letras e Ciências Humanas, Universidade de São Paulo, São Paulo, SP, Brasil.

Earle, T. (2009). Exchange systems in prehistory. In C. D. Dillian \& C. L. White (Eds.), Trade and exchange: archaeological studies from history and prehistory (pp. 205-217). New York: Springer.

Endo, L. Y. (2017). Metodologia de análise quantitativa de solos arqueológicos através de TXRF(Tese de doutorado). Universidade Estadual de Londrina, Londrina, PR, Brasil.

Fleming, M. I. D. (2008). Aplicação da arqueometria no estudo de coleções arqueológicas. Revista CPC, (6), 219-230. doi: https:// doi.org/10.11606/issn.1980-4466.v0i6p219-230

Furquim, L. P. (2018). Arqueobotânica e mudanças socioeconômicas durante o Holoceno Médio no sudoeste da Amazônia (Dissertação de mestrado). Museu de Arqueologia e Etnologia, Universidade de São Paulo, São Paulo, SP, Brasil.

Glascock, M. D. (1992). Characterization of archaeological ceramics at MURR by Neutron Activation Analysis and multivariate statistics. In H. Neff (Ed.), Chemical characterization of ceramic pastes in archaeology (pp. 11-26). Madison: Prehistory Press.
Glascock, M. D., \& Neff, H. (2003). Neutron activation analysis and provenance research in archaeology. Measurement Science and Technology, 14(9), 1516-1526. doi: https://doi. org/10.1088/0957-0233/14/9/304

Glascock, M. D., Speakman, R. J., \& Neff, H. (2007). Archaeometry at the University of Missouri Research Reactor and the provenance of obsidian artefacts in North America. Archaeometry, 49(2), 343-357. doi: https://doi.org/10.1111/ j.1475-4754.2007.00305.x

Goulart, E. P., Alves, M. A., Zandonadi, A. R., Munita, C. S., \& Paiva, R. P. (2005). Sítio Prado, estado de Minas Gerais: caracterização microestrutural e química de amostras de cerâmica indígena. Canindé, 6, 67-83.

Hazenfratz, R. (2014). Nêutrons, radiação e arqueologia: estudo de caso multianalítico de cerâmicas da Tradição Borda Incisa na Amazônia Central (Tese de doutorado). Unniversidade de São Paulo, São Paulo, SP, Brasil.

Hazenfratz, R., Mongeló, G. Z., Munita, C. S., \& Neves, E. G. (2012). Comparison of INAA elemental composition data between Lago Grande and Osvaldo archaeological sites in the Central Amazon: a first perspective. Journal of Radioanalytical and Nuclear Chemistry, 291(1), 43-48. doi: https://doi.org/10.1007/s10967-011-1251-3

Hazenfratz, R., Munita, C. S., Glascock, M. D., \& Neves, E. G. (2016). Study of exchange networks between two Amazon archaeological sites by INAA. Journal of Radioanalytical and Nuclear Chemistry, 309(1), 195-205. doi: https://doi. org/10.1007/s10967-016-4758-9

Hazenfratz, R., Munita, C. S., \& Neves, E. G. (2018). Neural Networks (SOM) applied to INAA data of chemical elements in archaeological ceramics from Central Amazon. STAR: Science \& Technology of Archaeological Research, 3(2), 334340. doi: https://doi.org/10.1080/20548923.2018.1470218

Heckenberger, M. J., Petersen, J. B., \& Neves, E. G. (1999). Village size and permanence in Amazonia: two archaeological examples from Brazil. Latin American Antiquity, 10(4), 353-376. doi: https://doi.org/10.2307/971962

Heckenberger, M. J., \& Neves, E. G. (2009). Amazonian archaeology. Annual Review of Anthropology, 38, 251-266. doi: https://doi.org/10.1146/annurev-anthro-091908-164310

International Atomic Energy Agency (IAEA). (Ed.). (2003). Nuclear Analytical Techniques in Archaeological Investigations (Technical Reports Series, 416). Vienna: International Atomic Energy Agency.

Karkanas, P., \& Goldberg, P. (2018). Reconstructing archaeological sites: understanding the geoarchaeological matrix. Hoboken: John Wiley \& Sons. 
Kern, C. D., Heron, A., Figueira, B. A. M., \& Costa, J. (2013). Pesquisas arqueométricas na Amazônia, com ênfase no material cerâmico. In J. C. Rubin de Rubin \& R. T. Silva (Orgs.), Geoarqueologia (pp. 91-111). Goiânia: Pontifícia Universidade Católica de Goiás.

Leite Neto, W. M. (2008). Tecnologia lítica dos grupos ceramistas da Chapada do Araripe: análise dos sítios arqueológicos do município de Araripina, Pernambuco, Brasil (Dissertação de mestrado), Universidade Federal de Pernambuco, Recife, PE, Brasil.

Lemonnier, P. (1992). Elements for an anthropology of technology (Anthropological Papers Series, 88). Ann Arbor: Museum of Anthropological Archaeology, University of Michigan.

Lima, H. P. (2008). História das caretas: a tradição borda incisa na Amazônia Central (Tese de doutorado). Museu de Arqueologia e Etnologia, Universidade de São Paulo, São Paulo, SP, Brasil.

Lima, H. P., \& Neves, E. G. (2011). Cerâmicas da tradição Borda Incisa/Barrancoide na Amazônia Central. Revista do Museu de Arqueologia e Etnologia, (21), 205-230. doi: https://doi. org/10.11606/issn.2448-1750.revmae.2011.89974

Lima, H. P., Barreto, C., \& Betancourt, C. J. (2016). Novos olhares sobre as cerâmicas arqueológicas da Amazônia. In C. Barreto, H. P. Lima \& C. J. Betancourt (Orgs.), Cerâmicas arqueológicas da Amazônia: rumo a uma nova síntese (pp. 19-31). Belém: IPHAN.

Luna, S. (2005). Os grupos ceramistas pré-históricos do baixo São Francisco. Clio Arqueológica, 19(2), 79-103.

Machado, J. S. (2005). Processos de formação: hipóteses sobre a variabilidade do registro arqueológico de um montículo artificial no sítio Hatahara, Amazonas. Revista de Arqueologia, 18(1), 9-24. doi: https://doi.org/10.24885/sab.v18i1.201

Maggetti, M. (1982). Phase analysis and its significance for technology and origin. In J. S. Olin \& A. D. Franklin (Eds.), Archaeological ceramics (pp. 121-133). Washington, DC: Smithsonian Institution Press.

Maranca, S., \& Meggers, B. (1980). Uma reconstituição de organização social baseada na distribuição de tipos de cerâmica num sítio habitação da tradição Tupiguarani. Pesquisas, 31, 227-247.

Michelaki, K., Braun, G. V., \& Hancock, R. G. V. (2015). Local clay sources as histories of human-landscape interactions: a ceramic taskscape perspective. Journal of Archaeological Method and Theory, 22(3), 783-827. doi: https://doi.org/10.1007/ s10816-014-9204-0

Mongeló, G. Z. (2011). Processos de interação entre os sítios Lago Grande e Oswaldo (AM) baseado no material cerâmico [Supl. 11]. Revista do Museu de Arqueologia e Etnologia, 109-114. doi: https://doi.org/10.11606/issn.2594-5939. revmaesupl.2011.113543
Munita, C. S. (2005). Contribuição da análise por ativação com nêutrons a estudos arqueométricos: estudo de caso. Canindé, 6, 151-181.

Munita, C. S., Alves, M. A., \& Paiva, R. P. (1997, junho). Characterization of Brazilian prehistoric ceramics. In Annals of the first research co-ordination meeting of the "Coordinated Research Program on nuclear analytical techniques in archaeological investigations", Smithsonian Institution, Conservation Analytical Laboratory, Washington, DC, USA.

Munita, C. S., Paiva, R. P., Alves, M. A., Oliveira, P. M. S., \& Momose, E. F. (2000a). Contribution of neutron activation analysis to archaeological studies. Journal of Trace and Microprobe Techniques, 18(3), 381-387.

Munita, C. S., Paiva, R. P., Alves, M. A., Momose, E. F, \& Saiki, M. (2000b). Chemical characterization by INAA of Brazilian ceramics and cultural implications. Journal of Radioanalytical and Nuclear Chemistry, 244(3), 575-578. doi: https://doi. org/10.1023/A:1006757031293

Munita, C. S., Paiva, R. P., Alves, M. A., Oliveira, P. M. S., \& Momose, E. F. (2001a). Major and trace element characterization of prehistoric ceramic from Rezende archaeological site. Journal of Radioanalytical and Nuclear Chemistry, 248(1), 93-96. doi: https://doi.org/10.1023/A:1010682209370

Munita, C. S., Paiva, R. P., Oliveira, P. M. S., Momose, E. F., Plá, R., Moreno, M., . . . Kohnenkamp, I. (2001b). Intercomparison among three activation analysis laboratories in South America. Journal of Trace and Microprobe Techniques, 19(2), 189-197. doi: https://doi.org/10.1081/TMA-100002208

Munita, C. S., Paiva, R. P., Alves, M. A., Oliveira, P. M. S., \& Momose, E. F. (2003). Provenance study of archaeological ceramic. Journal of Trace and Microprobe Techniques, 21(4), 697-706. doi: https://doi.org/10.1081/TMA-120025819

Munita, C. S., Nascimento, A., Schreiber, S. B., Luna, S., \& Oliveira, P. M. S. (2004). Chemical study of some ceramics from Brazilian northeast. Journal of Radioanalytical and Nuclear Chemistry, 259(2), 305-309. doi: https://doi.org/10.1023/ B:JRNC.0000017308.65405.b5

Munita, C. S., Silva, M. A., Silva, F. A., \& Oliveira, P. M. S. (2005). Archaeometric study of clay deposits from the Indigenous Land of the Assurini do Xingu. Instrumentation Science and Technology, 33(2), 161-173. doi: https://doi.org/10.1081/ Cl-200048058

Munita, C. S., Toyota, R. G., Neves, E. G., Demartini, C. C., Schaan, D. P., \& Oliveira, P. M. S. (2011). Chemical characterization of Marajoara Pottery. In International Atomic Energy Agency (IAEA) (Ed.), Nuclear techniques for cultural heritage research (pp.133-146). Vienna: International Atomic Energy Agency. 
Munita, C. S., Carvalho, P. R., Oliveira, C. A., Amaral, A. M., \& Sullasi, H. L. (2018). Estudo da mobilidade logística a partir da caracterização química da cerâmica do "Sítio Capim" em Araripina, Pernambuco, Brasil. Cadernos do LEPAARQ, 15(30), 179-190.

Munita, C. S., Glascock, M. D., \& Hazenfratz, R. (2019). Neutron Activation Analysis: an overview. In A. Ur-Rahman \& S. A. Ozkan (Eds.), Recent advances in analytical techniques (Vol. 3, pp. 179-227). Sharjah: Bentham Science Publishers.

Neves, E. G. (2011). Archaeological cultures and past identities in the pre-colonial Central Amazon. In A. Hornborg \& J. D. Hill (Eds.), Ethnicity in ancient Amazonia: reconstructing past identities from archaeology, linguistics, and ethnohistory (pp. 31-56). Boulder: University Press of Colorado.

Neves, E. G., Petersen, J. B., Bartone, R. N., \& Heckenberger, M. J. (2004). The timing of Terra Preta formation in the Central Amazon: archaeological data from three sites. In B. Glaser \& W. I. Woods (Eds.), Amazonian dark earths: explorations in space and time (pp. 125-134). Berlin: Springer-Verlag.

Neves, E. G., \& Petersen, J. B. (2006). Political economy and preColumbian landscape transformations in Central Amazonia. In W. Balée \& C. L. Erickson (Eds.), Time and complexity in Historical Ecology: studies in the Neotropical lowlands (pp. 279-309). New York: Columbia University Press.

Neves, E. G., Munita, C. S., Hazenfratz, R., \& Mongeló, G. Z. (2019). Ancient exchange networks in Central Amazon. In M. D. Glascock, H. Neff \& K. J. Vaughn (Eds.), Ceramics of the indigenous cultures of South America: studies of production and exchange through compositional analysis (pp. 231-239). Albuquerque: University of New Mexico Press.

Nogueira, A. L., \& Munita, C. S. (2019, outubro). The effect of data standardization in cluster analysis. In Annals of the International Nuclear Atlantic Conference - INAC, Associação Brasileira de Energia Nuclear, Santos, Brasil.

Nunes, K. P. (2009). Estudos arqueométricos do sítio arqueológico Hatahara (Dissertação de mestrado). Instituto de Pesquisas Energéticas e Nucleares, Universidade de São Paulo, São Paulo, SP, Brasil.

Nunes, K. P., Munita, C. S., Oliveira, P. M. S., Neves, E. G., \& Tamanaha, E. K. (2010). Caracterización química de cerámicas del sitio Hatahara, Amazonia - Brasil. In Instituto Nacional de Patrimonio Cultural (Ed.), Las técnicas analíticas nucleares y el patrimonio cultural (pp. 54-72). Quito: Ministerio de Cultura del Ecuador - Instituto Nacional de Patrimonio Cultural.

Nunes, K. P., Toyota, R. G., Oliveira, P. M. S., Neves, E. G., Soares, E. A. A., \& Munita, C. S. (2013). Preliminary compositional evidence of provenance of ceramics from Hatahara archaeological site, Central Amazonia. Journal of Chemistry, 2013(1), 1-6. doi: https://doi.org/10.1155/2013/701748
Oliveira, P. M. S., \& Munita, C. S. (2003, julho). Influência do valor crítico na detecção de valores discrepantes em arqueometria. In Anais da $48^{\circ}$ Reunião anual da Sociedade Brasileira de Biometria, Sociedade Brasileira de Biometria, Lavras, Brasil.

Oliveira, P. M. S., Munita, C. S., \& Hazenfratz, R. (2010). Comparative study between three methods of outlying detection on experimental results. Journal of Radioanalytical and Nuclear Chemistry, 283(2), 433-437. doi: https://doi. org/10.1007/s10967-009-0382-2

Pessoa, C. (2015). Os contextos arqueológicos e a variabilidade artefatual da ocupação Jatuarana no alto rio Madeira (Dissertação de mestrado). Universidade Federal do Pará, PA, Belém, Brasil.

Pollard, A. M., Batt, C. M., Stern, B., \& Young, S. M. M. (2007). Analytical chemistry in archaeology. New York: Cambridge University Press.

Portocarrero, R. A. C. (2007). A variabilidade espacial no sítio Osvaldo: estudo de um assentamento da Tradição Barrancoide na Amazônia Central (Dissertação de mestrado). Museu de Arqueologia e Etnologia, Universidade de São Paulo, São Paulo, SP, Brasil.

Pugliese Jr., F. A. (2018). A história indígena profunda do sambaqui Monte Castelo: um ensaio sobre a longa duração da cerâmica e das paisagens no sudoeste amazônico (Tese de doutorado). Museu de Arqueologia e Etnologia, Universidade de São Paulo, São Paulo, SP, Brasil.

Rebellato, L., Woods, W. I., \& Neves, E. G. (2009). PreColumbian settlement dynamics in the Central Amazon. In W. I. Woods, W. G. Teixeira, J. Lehmann, C. Steiner, A. M. G. A. Winklerprins \& L. Rebellato (Eds.), Amazonian Dark Earths: Wim Sombroek's vision (pp. 15-31). New York: Springer.

Rice, P. M. (1987). Pottery analysis: a sourcebook. Chicago: The University of Chicago Press.

Rizzutto, M. A., Added, N., Tabacniks, M. H., Curado, J. F., \& Pascholati, P. R. (2009). Métodos analíticos não destrutivos para análise de obras de arte [Supl. 8]. Revista do Museu de Arqueologia e Etnologia, 177-188. doi: https://doi. org/10.11606/issn.2594-5939.revmaesupl.2009.113520

Rostain, S., \& Betancourt, C. J. (Eds.). (2017). Las siete maravillas de la Amazonía precolombina. La Paz: Bonner Altamerika Sammlung und Studien - Plural Editores.

Santos, J. O. (2007). Estudos arqueométricos de sítios arqueológicos do baixo São Francisco (Tese de doutorado). Instituto de Pesquisas Energéticas e Nucleares, Universidade de São Paulo, São Paulo, SP, Brasil. 
Santos, J. O., Munita, C. S., Valério, M. E. G., Vergne, M. C. Z., \& Oliveira, P. M. S. (2006). Determination of trace elements in archaeological ceramics and application of Kernel Density Estimates: implications for the definition of production locations. Journal of Radioanalytical and Nuclear Chemistry, 269(2), 441-445. doi: https://doi.org/10.1007/s10967-006-0405-1

Santos, J. O., Munita, C. S., Valério, M. E. G., Vergne, M. C. Z., \& Oliveira, P. M. S. (2008). Correlations between chemical composition and provenance of Justino site ceramics by INAA. Journal of Radioanalytical and Nuclear Chemistry, 278(1), 185-190. doi: https://doi.org/10.1007/s10967-007-7236-6

Santos, J. O., Munita, C. S., Toyota, R. G., Vergne, M. C. Z., Silva, R. S., \& Oliveira, P. M. S. (2009). The archaeometry study of the chemical and mineral composition of pottery from Brazil's northeast. Journal of Radioanalytical and Nuclear Chemistry, 281(2), 189-192. doi: https://doi.org/10.1007/s10967-009-0119-2

Santos, J. O., Reis, M. S., Munita, C. S., \& Silva, J. E. (2017). BoxCox transformation on dataset from compositional studies of archaeological potteries. Journal of Radioanalytical and Nuclear Chemistry, 311(2), 1427-1433. doi: https://doi.org/10.1007/ s10967-016-4987-y

Saunaluoma, S., Pärssinen, M., \& Schaan, D. P. (2018). Diversity of precolonial earthworks in the Brazilian state of Acre, southwestern Amazonia. Journal of Field Archaeology, 43(5), 362-379. doi: https://doi.org/10.1080/00934690.2018.1483686

Schaan, D. P. (2004). The Camutins chiefdom: rise and development of social complexity on Marajó Island, Brazilian Amazon (Tese de doutorado). Faculty of Arts and Sciences, University of Pittsburgh, Pittsburgh.

Schiffer, M. B., \& Skibo, J. M. (1997). The explanation of artifact variability. American Antiquity, 62(1), 27-50. doi: https://doi. org/10.2307/282378

Silva, F. A. (2000). As tecnologias e seus significados: um estudo da cerâmica dos Asurini do Xingu e da cestaria dos Kayapó-Xikrin sob uma perspectiva etnoarqueológica (Tese de doutorado). Universidade de São Paulo, São Paulo, SP, Brasil.

Silva, F. A. (2016). Tipos cerâmicos ou modos de vida? Etnoarqueologia e as tradições arqueológicas cerâmicas na Amazônia. In C. Barreto, H. P. Lima \& C. J. Betancourt (Orgs.), Cerâmicas arqueológicas da Amazônia: rumo a uma nova síntese (pp. 4049). Belém: IPHAN.

Silva, L. V. (2013). O antropogênico e o geogênico na sedimentação préhistórica de Lagoa Santa: estudo geoarqueológico do sítio Lapa do Niáctor (Dissertação de mestrado). Universidade Federal de Minas Gerais, Belo Horizonte, MG, Brasil.

Silva, R. P., Tudela, D. R. G., Munita, C. S., Hazenfratz, R., Tatumi, S. H., Yee, M., \& Mittani, J. C. R. (2017). Firing temperature determination and thermoluminescence dating of a brick with cuneiform characters found in the ruins of Ancient Babylon. Revista do Museu de Arqueologia e Etnologia, 28, 58-69.
Tamanaha, E. K. (2012). Ocupação Polícroma no baixo e médio rio Solimões, estado do Amazonas (Dissertação de mestrado). Museu de Arqueologia e Etnologia, Universidade de São Paulo, São Paulo, SP, Brasil.

Tamanaha, E. K. (2016). A fase Guarita nos contextos do baixo rio Solimões. In C. Barreto, H. P. Lima \& C. J. Betancourt (Orgs.), Cerâmicas arqueológicas da Amazônia: rumo a uma nova síntese (pp. 365-372). Belém: IPHAN.

Tamanaha, E. K., \& Py-Daniel, A. R. (2009). Sítio Hatahara: estruturas funerárias, residenciais ou ambas? [Supl. 8]. Revista do Museu de Arqueologia e Etnologia, 63-73. doi: https://doi.org/10.11606/ issn.2594-5939.revmaesupl.2009.113509

Toyota, R. G. (2009). Caracterização química da cerâmica Marajoara (Dissertação de mestrado). Universidade de São Paulo, São Paulo, SP, Brasil.

Tudela, D. R. G. (2013). Caracterização físico-química de sedimentos do sítio arqueológico Lapa Grande de Taquaraçu, MG (Dissertação de mestrado). Universidade de São Paulo, São Paulo, SP, Brasil.

Tudela, D. R. G., Tatumi, S. H., Yee, M., Brito, S. L. M., Morais, J. L., Morais, D., . . . Hazenfratz, R. (2012). TL, OSL and C-14 dating results of the sediments and bricks from a mummified nuns' grave. Anais da Academia Brasileira de Ciências, 84(2), 237244. doi: https://doi.org/10.1590/S0001-37652012005000031

Vergne, M. C. S. (2004). Arqueologia do baixo São Francisco: estruturas funerárias do sítio Justino - região de Xingó, Canindé do São Francisco, Sergipe (Tese de doutorado). Museu de Arqueologia e Etnologia, Universidade de São Paulo, São Paulo, SP, Brasil.

Villagran, X. S., Strauss, A., Miller, C., Ligouis, B., \& Oliveira, R. (2017). Buried in ashes: site formation processes at Lapa do Santo rockshelter, east-central Brazil. Journal of Archaeological Science, 77, 10-34. doi: https://doi.org/10.1016/j. jas.2016.07.008

Watling, J., Shock, M. P., Mongeló, G. Z., Almeida, F. O., Kater, T., Oliveira, P. E., \& Neves, E. G. (2018). Direct archaeological evidence for southwestern Amazonia as an early plant domestication and food production centre. PLOS ONE, 13(7), e0199868. doi: https://doi.org/10.1371/journal.pone.0199868

Zimpel, C. A., \& Pugliese Jr., F. A. (2016). A fase Bacabal e suas implicações para a interpretação do registro arqueológico no médio rio Guaporé, Rondônia. In C. Barreto, H. P. Lima \& C. J. Betancourt (Orgs.), Cerâmicas arqueológicas da Amazônia: rumo a uma nova síntese (pp. 420-434). Belém: IPHAN.

Zuse, S. (2016). Variabilidade cerâmica e diversidade cultural no alto rio Madeira. In C. Barreto, H. P. Lima \& C. J. Betancourt (Orgs.), Cerâmicas arqueológicas da Amazônia: rumo a uma nova síntese (pp. 385-401). Belém: IPHAN. 


\section{CONTRIBUIÇÃO DOS AUTORES}

C. S. Munita contribuiu com conceituação, investigação, metodologia, software, validação e escrita (rascunho original, revisão e edição); N. Batalla com conceituação, investigação, metodologia, validação, visualização e escrita (rascunho original, revisão e edição); A. F. Costa com conceituação, investigação, metodologia, validação, visualização e escrita (rascunho original, revisão e edição); J. F. Barros com conceituação, investigação, metodologia, validação, visualização e escrita (rascunho original, revisão e edição); A. L. Nogueira com conceituação, investigação, metodologia, validação, visualização e escrita (rascunho original, revisão e edição); P. R. Carvalho com conceituação, investigação, metodologia, validação, visualização e escrita (rascunho original, revisão e edição); P. R. Carvalho com conceituação, investigação, metodologia, validação, visualização e escrita (rascunho original, revisão e edição). 
